Article

\title{
Consumer Preference for Eco-Labeled Seafood in Korea
}

\author{
Bong-Tae Kim ${ }^{1}$ and Min-Kyu Lee ${ }^{2, *(1)}$ \\ 1 Fisheries Research Division, Korea Maritime Institute, 26 Haeyang-Ro 301Beon-Gil, Yeongdo-Gu, \\ Busan 49111, Korea; btkim@kmi.re.kr \\ 2 Graduate School of Management of Technology, Pukyong National University, 365 Sinseon-Ro, Nam-Gu, \\ Busan 48547, Korea \\ * Correspondence: minkyu@pknu.ac.kr; Tel.: +82-51-629-5649
}

Received: 17 August 2018; Accepted: 12 September 2018; Published: 13 September 2018

check for updates

\begin{abstract}
In Korea, fishery managers, eco-labeled program operators, and the government need detailed information regarding individual-level preferences for eco-labeled seafood. This study aims to identify the determinants of consumer preference for such seafood. Specifically, an ordered probit model is estimated by using micro-survey data obtained from interviews of 2773 randomly selected Korean households. Overall, the estimation results reveal that the chosen model is appropriate to analyze consumer preference for eco-labeled seafood. The coefficients of consumption frequency, the importance of price, the confirmation of origin, residential area, and household income are statistically meaningful. If consumers consider price an important factor, their consumption of eco-labeled seafood may decrease. Moreover, consumers with interest in the origin of seafood are more likely to accept eco-labeled seafood. To increase the consumption of eco-labeled seafood, it is recommended to develop products designed specifically for segmented markets and promote functional features. The findings can provide a valuable guideline to marketing managers and policy makers for designing effective strategies regarding eco-labeled seafood.
\end{abstract}

Keywords: consumer preference; eco-labeled seafood; ordered probit model; Korea

\section{Introduction}

According to the Food and Agriculture Organization [1], global fish production reached 171 million tons in 2016, with aquaculture accounting for $47 \%$ of the total produce. While the capture fisheries production has decreased from 92.2 million tons in 2011 to 90.9 million tons in 2016, global aquaculture production has grown from 61.8 million tons to 80.0 million tons in the same period [1]. Capture fisheries depend on natural stocks, which are often overexploited. The proportion of fish stocks within biologically unsustainable levels has shown an increasing trend from 10\% in 1974 to $33 \%$ in 2015 [1]. The situation is not very different from that in Korea, where the catch in coastal and offshore fisheries fell from 1.5 million tons in the 1980s to less than 1 million tons in 2016 [2].

The concern about the overexploitation of natural stocks has resulted in several eco-labeling initiatives in resource-based industries [3]. To offer incentives for fishery managers who operate sustainable fisheries, various programs for eco-labeling seafood products have been suggested. For instance, in 1997, the Marine Stewardship Council was founded via cooperation between the World Wildlife Fund and Unilever [4]. Through eco-labeling, the MSC has tried to make a contribution to the soundness of the global oceans by recognizing sustainable fishing practices and influencing consumers' choice of seafood. Moreover, the Aquaculture Stewardship Council was established in 2010 as an international non-profit organization that manages the leading certification and labeling program for 
responsible aquaculture. Recently, there has been a growing consensus in Korea that eco-labeling should be actively adopted as a new resource management tool based on consumer preferences [5].

Eco-labels convey information on the environmental attributes of goods and can influence consumers to purchase environment-friendly products [6]. Moreover, eco-labeling generates market-based incentives in the form of a price premium to compensate producers who provide sustainable products. Because certification programs entail some degree of unavoidable cost, consumers' willingness to pay (WTP) a price premium for eco-labeled seafood will affect program achievement [3]. The presence of a price premium for eco-labeled seafood is at the center of the eco-labeling issue [7]. Thus, analyzing consumer preference for or acceptance of eco-labeled seafood becomes increasingly meaningful for ensuring the success of such programs. Consumer preference for seafood has been considered as a main factor in determining consumption. From this perspective, the government, fishery managers, and eco-labeled program operators need detailed information on individual-level preferences for eco-labeled seafood in Korea. However, because of insufficient data, it is not easy to determine recent consumption patterns and preferences. Therefore, to examine the determinants of the acceptance of eco-labeled seafood in Korea is significant.

Some studies have measured the determinants of seafood consumption by employing choice models and successfully applying techniques to describe choice behavior [8-15]. Some case studies also evaluate consumer preference for eco-labeled seafood [16-19]. Jaffry et al. [16] conducted a choice experiment for eco-labeled seafood products for UK consumers. Xu et al. [17] evaluated Chinese consumers' WTP for eco-labeled seafood. Using a choice experiment, Uchida et al. [18] evaluated consumers' preference for eco-labeled seafood in Japan. Pérez-Ramírez et al. [19] applied an ordered probit model to examine consumer acceptance of eco-labeled seafood in Mexico. Moreover, Jonell et al. [20] studied which consumer characteristics affect demand for eco-labeled seafood in Sweden. Richter et al. [21] investigated the motivation behind two selected ways of reaching sustainable seafood in regards to the use of sustainable seafood labels and sustainable seafood guides for Norwegian consumers. As far as we know, only a few studies applied an ordered probit model to measure consumer preference for eco-labeled seafood in Korea.

This study uses cross-sectional data to estimate the acceptance of eco-labeled seafood. A total of 2773 households were interviewed with the help of a professional survey company to collect data for analysis. The study aims to estimate socio-demographic determinants which influence the preference for eco-labeled seafood in Korea, by employing an ordered probit model. The findings of this study will be useful from a methodological perspective given the model's scarce application, as previously mentioned. This study can be applied to market segmentation to identify groups with high WTP for eco-labeled seafood. The results are expected to provide fishery managers, eco-labeled program operators, and the government with useful information for designing strategies that enhance the acceptance of eco-labeled seafood. This study can contribute to the increased use of ordered probit models, thus laying the groundwork for evaluations of the consumer preference for eco-labeled seafood in Korea.

The remainder of this paper is structured as follows. Section 2 presents the proposed theoretical model. Section 3 deals with the data, while the penultimate section shows the empirical results. Section 5 concludes.

\section{Model}

The conceptual framework of the model is developed on the basis of the underlying assumption that the consumer preference for eco-labelled seafood is affected by socio-economic factors, product experience, and product perceptions. In terms of surveys concerning the preference for eco-labelled seafood, open-ended questions are not suggested, as they will result in overestimating consumption preference. Instead, ordered response models have been widely applied to the analysis of consumer seafood preference [9-13]. Specifically, this study considers an ordered probit model to evaluate individuals' preference for eco-labelled seafood measured by a categorical, ordered dependent variable. 
The ordered probit model is a valid framework if answers are ordinal [9]. For each individual $i=1,2, \ldots, N$, the model includes a stochastic part identifying the degree of consumption preference. By leveraging the random utility modeling technique, the model assumes that the consumer preference is defined as follows:

$$
z_{i}^{*}=w_{i}^{\prime} \beta+\varepsilon_{i}
$$

The latent regression model in (1) describes the underlying continuous preference of eco-labeled seafood as $z_{i}^{*}$. As usual, $z_{i}^{*}$ is unobserved, and we can observe ordered responses only through a censoring mechanism. Given the ordered choice model, the utility is assumed to be included in a certain utility interval. The explanation of the ordered result as a censoring of continuous consumption offers a trustworthy guide to model suitability [22]. The latent variable $z_{i}^{*}$ depends on two components. The first is the linear combination of the vector of independent variables $w_{i}$ that may affect the preference for eco-labeled seafood and parameter vector $\beta$. The latter means a stochastic term $\varepsilon_{i}$ that indicates the unobservable impacts on the selection of individual $i$. The observed ordered dependent variable $z_{i}$ is given by the following equation:

$$
\begin{array}{rlrl}
z_{i}=0 & & \text { if } \mathrm{z}_{i}^{*} \leq \lambda_{0} \\
=1 & \text { if } \lambda_{0}<z_{i}^{*} \leq \lambda_{1} \\
=2 & \text { if } \lambda_{1}<z_{i}^{*} \leq \lambda_{2} \\
& \quad \vdots \\
=J & \text { if } \lambda_{J-1}<z_{i}^{*}
\end{array}
$$

The $\lambda \mathrm{s}$ are category threshold parameters to be estimated along with $\beta \mathrm{s}$, subject to constraint $\lambda_{0}<\lambda_{1}<\cdots<\lambda_{J-1}$. The threshold parameters represent positions at which the variation in the latent preference is high, causing an individual to change the level of preference. The respondents could answer any of the preference categories listed in the survey with their own $z_{i}^{*}$, if asked to do so [9]. Instead, they chose the category that indicates their consumption preference level among five possible choices.

Specifically, the dependent variable takes the following possible values: very unfavorable $(z=0)$, unfavorable $(z=1)$, indifferent $(z=2)$, favorable $(z=3)$, and very favorable $(z=4)$. The probability associated with the observed outcomes is formulated as:

$$
\begin{aligned}
\operatorname{Prob}\left(z_{i}=j\right) & =\operatorname{Prob}\left(\lambda_{j-1}<z_{i}^{*}=w_{i}{ }^{\prime} \beta+\varepsilon_{i} \leq \lambda_{j}\right) \\
& =\operatorname{Prob}\left(\lambda_{j-1}-w_{i} \beta<\varepsilon_{i} \leq \lambda_{j}-w_{i}{ }^{\prime} \beta\right) \\
& =F\left(\lambda_{j}-w_{i}{ }^{\prime} \beta\right)-F\left(\lambda_{j-1}-w_{i}{ }^{\prime} \beta\right)
\end{aligned}
$$

where $F(\cdot)$ is the cumulative density function of $\varepsilon_{i}$. Given the ordered probit model, we specify $F(\cdot)$ as the cumulative probability function of the univariate normal distribution. The likelihood function and log-likelihood function are expressed, respectively, as:

$$
\begin{gathered}
L=\prod_{i=1}^{N} \prod_{j=0}^{J}\left\{F\left(\lambda_{j}-w_{i}{ }^{\prime} \beta\right)-F\left(\lambda_{j-1}-w_{i}{ }^{\prime} \beta\right)\right\}^{z_{i j}} \\
\log L=\sum_{i=1}^{N} \sum_{j=0}^{J} z_{i j} \log \left\{F\left(\lambda_{j}-w_{i}{ }^{\prime} \beta\right)-F\left(\lambda_{j-1}-w_{i}{ }^{\prime} \beta\right)\right\}
\end{gathered}
$$

where $y_{i j}$ is 1 if individual $i$ selects preference category $j$, and 0 otherwise. The parameters are estimated by maximum likelihood estimation [23]. 
The estimated $\beta$ coefficients do not precisely indicate the marginal impacts of the independent variables. According to Greene and Hensher [22], the marginal effect in an ordered probit model is expressed by:

$$
\begin{aligned}
\frac{\partial \operatorname{Prob}\left(z_{i}=j\right)}{\partial w_{i k}} & =\frac{\partial\left\{F\left(\lambda_{j}-w_{i}^{\prime} \beta\right)-F\left(\lambda_{j-1}-w_{i}^{\prime} \beta\right)\right\}}{\partial w_{i k}} \\
& =\left\{F^{\prime}\left(\lambda_{j}-w_{i}^{\prime} \beta\right)-F^{\prime}\left(\lambda_{j-1}-w_{i}^{\prime} \beta\right)\right\} \beta_{k} \\
& =\left\{f\left(\lambda_{j}-w_{i}^{\prime} \beta\right)-f\left(\lambda_{j-1}-w_{i}^{\prime} \beta\right)\right\} \beta_{k}
\end{aligned}
$$

where $f(\cdot)$ means the density function of the univariate normal distribution. For a continuous variable, the marginal impact means the variation in the expected probability due to one point change in the independent variable. The marginal impact of a dummy variable indicates the gap between the two probabilities, with and without the variable [22].

\section{Data}

\subsection{Survey Instrument}

A survey of households was conducted from June to July 2017. The whole of South Korea was selected as the survey area. The survey was administered to household heads and home-makers aged between 20 and 69 years. A professional polling company, Macromill Embrain, conducted the entire process of a stratified random sampling by region and carrying out the survey. Given that each region composes a stratum, the allocated number of households was randomly decided within each region. The company tried to ensure that the sample characteristics reflect the population characteristics well. The internet-based survey was administered to 2773 households to examine their preference for eco-labeled seafood. In other words, respondents accessed the survey site and answered many questions through online survey platform designed by the professional polling company. Sample size in this study guarantees statistical validity with a low sampling error as it is far more than 1000, the minimum terms of sample size recommended by Korea Development Institute [24]. We selected four representative fish species, namely, flatfish, salmon, tuna, and octopus (Octopus minor). These species are commonly consumed in Korea, and represent cultured, imported, deep-sea, and coastal fish species, respectively. Figure 1 shows the annual food supply per capita per day in Korea. For example, annual tuna supply per capita per day in Korea was $4.0 \mathrm{~g}$ in 2015.

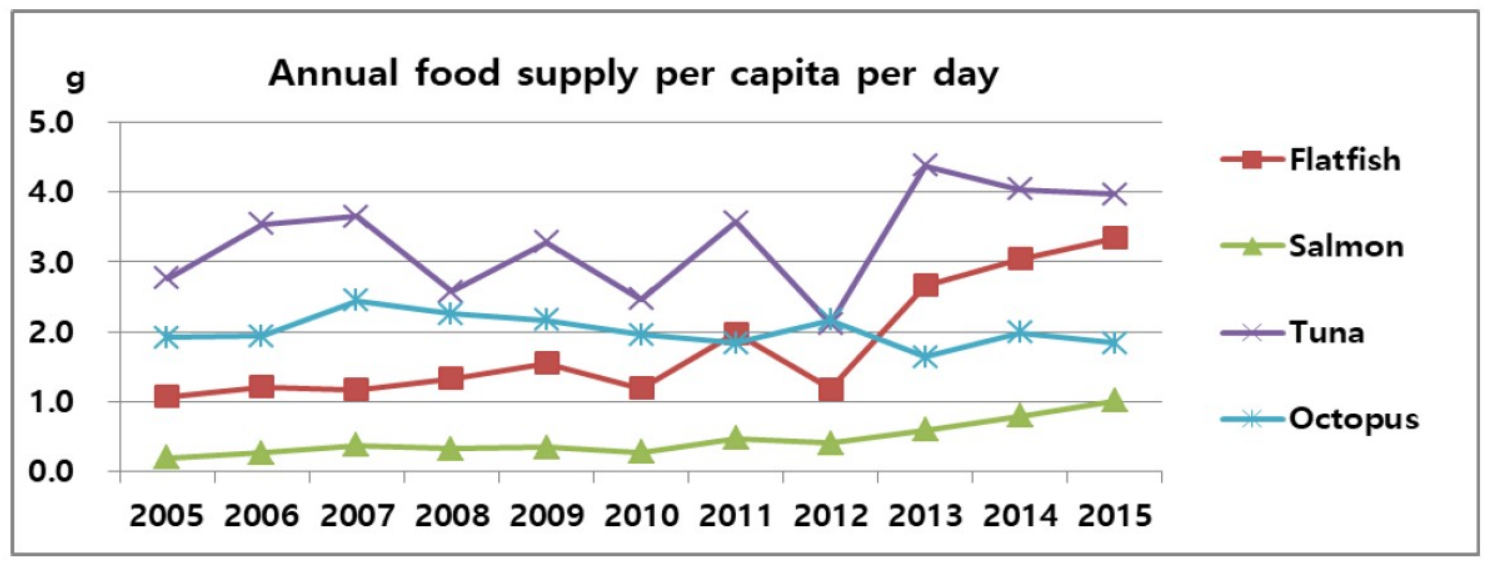

Figure 1. Annual food supply per capita per day [25].

We considered various information regarding seafood consumption behavior to organize the survey. The questionnaire was complemented by specialists of the polling firm. Before the survey, a pre-test with 30 persons was implemented to examine their comprehension of the questions. Based on the pre-test results, errors were rectified and the questionnaire was refined. The confirmed questionnaire referred to the pre-test respondents' opinion and the counsel of the survey specialists. The survey encompassed a description of the survey's goal as well as the composition of the interviews. 
The survey questionnaire was composed of three general categories: (1) introductory questions such as the preference for eco-labeled seafood; (2) questions on consumption behaviors, and (3) questions regarding the socio-demographic features.

\subsection{Sample Statistics}

Table 1 provides the definition and sample descriptive statistics of the variables of the data set. All variables except Frequency, Confirm, and Income are dummy variables that take the value of 0 or 1 . The mean of a dummy variable indicates the percentage of corresponding respondents of the total sample size. For example, the mean of Region1 is 0.226 , which shows that the percentage of respondents who lived in Seoul of the total respondents was $22.6 \%$. The standard deviation of a dummy variable is calculated as $\sqrt{\text { Mean } \times(1-\text { Mean })}$. Thus, if the mean of a dummy variable is close to 0 or 1 , the standard deviation will be close to 0 .

Among the survey questions, one significant question pertaining to preference for eco-labeled seafood is, "If eco-labeled seafood was available for sale with a higher price compared to non-labeled seafood, would you prefer the eco-labeled seafood rather than the non-labeled? Please select the most appropriate category of consumption preference". Given that the level of consumption preference was encoded as an ordered response, it was divided into a five-point Likert scale, which consists of two negative choices (very unfavorable, unfavorable), one neutral (indifferent), and two positive choices (favorable and very favorable). For example, $46.4 \%$ of the respondents answered that they were favorable to eco-labeled seafood, and $40.5 \%$ of the respondents were indifferent to eco-labeled seafood.

The consumption preference can be affected by product quality, product awareness, and beliefs [9]. Thus, to identify such factors, questions in consumption frequency, the importance of freshness and price, and confirmation of origin were included. Concerning where seafood was most likely to be consumed, $68.5 \%$ of the respondents stated that they preferred eating seafood outside than at home. The average frequency of seafood consumption per month was 2.7. Regarding consumption factors, $82.9 \%$ respondents selected freshness of fish as the most important factor. A five-point Likert scale was employed to estimate the level of confirmation of origin. The average value was 3.8 , indicating a rather strong tendency to confirm the origin of the product.

Socio-demographic variables such as gender, age, residential area, the number of household members and children, job, and income were considered. Half of respondents were female. The sample aged 30-59 years old accounted for $69 \%$ of the total. Regarding residential area, more than half of the respondents lived in Gyeonggi, Incheon, and Seoul. The proportion of respondents who lived in Gyeonggi and Incheon was 31.1\%, which approximates the published proportion of the number of households in the region, $28.7 \%$ [26]. Moreover, $40.9 \%$ of respondents stated that their household consists of four members, and $58.7 \%$ of the sample had at least one child. In terms of occupation, $44.9 \%$ of the respondents were included in the office worker group. In terms of monthly household income, the mean value of the sample was about USD 4322 (KRW 4.94 million). The mean monthly income in South Korea for the third quarter of 2017 was USD 3968 (KRW 4.54 million), which is similar to the reported average income of the study sample [27].

When referring to prior studies, we can hypothesize that respondents with lower sensitivity to price or a higher income tend to have higher preference of eco-labeled seafood. Other socio-economic variables such as age, region, occupation, presence of children, and the number of household members are expected to affect the consumer preference. Moreover, we assume that experience variables like consumption frequency, interest in country of origin, consumed species, and consumption place can exert an effect on the preference. On the contrary, gender and sensitivity to freshness are not expected to affect the consumer preference for eco-labeled seafood. 
Table 1. Definitions and sample descriptive statistics.

\begin{tabular}{|c|c|c|c|c|c|c|c|}
\hline Type & Variable & Description & & Mean & $\begin{array}{l}\text { Standard } \\
\text { Deviation }\end{array}$ & Min & Max \\
\hline \multirow{5}{*}{$\begin{array}{l}\text { Dependent } \\
\text { variable }\end{array}$} & \multirow{5}{*}{ Prefer } & \multirow{5}{*}{$\begin{array}{l}\text { Consumer preference for } \\
\text { eco-labeled seafood }\end{array}$} & Very unfavorable $=0$ & 0.004 & 0.066 & 0 & 1 \\
\hline & & & Unfavorable $=1$ & 0.056 & 0.229 & 0 & 1 \\
\hline & & & Indifferent $=2$ & 0.405 & 0.491 & 0 & 1 \\
\hline & & & Favorable $=3$ & 0.464 & 0.499 & 0 & 1 \\
\hline & & & Very favorable $=4$ & 0.072 & 0.258 & 0 & 0 \\
\hline \multirow{32}{*}{$\begin{array}{l}\text { Independent } \\
\text { variable }\end{array}$} & Flatfish & \multirow{4}{*}{$\begin{array}{l}\text { Species } \\
(\text { yes }=1 ; \text { no }=0)\end{array}$} & Flatfish & 0.270 & 0.444 & 0 & 1 \\
\hline & Salmon & & Salmon & 0.261 & 0.439 & 0 & 1 \\
\hline & Tuna & & Tuna & 0.225 & 0.418 & 0 & 1 \\
\hline & Octopus & & Octopus & 0.244 & 0.429 & 0 & 1 \\
\hline & Outdoor & \multicolumn{2}{|l|}{$\begin{array}{c}\text { Consumption place } \\
(\text { outdoor }=1 ; \text { home }=0)\end{array}$} & 0.685 & 0.465 & 0 & 1 \\
\hline & Domestic & \multicolumn{2}{|c|}{$\begin{array}{c}\text { Country of origin } \\
(\text { domestic }=1 ; \text { import }=0)\end{array}$} & 0.561 & 0.496 & 0 & 1 \\
\hline & Frequency & \multicolumn{2}{|c|}{ Log (frequency of seafood consumption per month) } & 0.702 & 0.703 & 0 & 3.401 \\
\hline & Fresh & \multirow{2}{*}{$\begin{array}{l}\text { The most important consumption factors } \\
\text { (yes }=1 ; \text { no }=0 \text { ) }\end{array}$} & Freshness & 0.829 & 0.377 & 0 & 1 \\
\hline & Price & & Price & 0.130 & 0.336 & 0 & 1 \\
\hline & Confirm & \multicolumn{2}{|c|}{$\begin{array}{c}\text { Level of confirmation of origin } \\
(\text { very low }=1 ; \text { low }=2 ; \text { indifferent }=3 ; \text { high }=4 ; \text { very high }=5)\end{array}$} & 3.841 & 0.749 & 1 & 5 \\
\hline & Female & \multicolumn{2}{|c|}{ Gender of the respondent $($ female $=1 ;$ male $=0)$} & 0.524 & 0.500 & 0 & 1 \\
\hline & Age20 & \multirow{5}{*}{$\begin{array}{l}\text { Age of the respondent } \\
\quad(\text { yes }=1 ; \text { no }=0)\end{array}$} & $20-29$ & 0.185 & 0.389 & 0 & 1 \\
\hline & Age30 & & $30-39$ & 0.226 & 0.418 & 0 & 1 \\
\hline & Age40 & & $40-49$ & 0.233 & 0.423 & 0 & 1 \\
\hline & Age50 & & $50-59$ & 0.231 & 0.421 & 0 & 1 \\
\hline & Age60 & & $60-69$ & 0.125 & 0.331 & 0 & 1 \\
\hline & Region1 & \multirow{6}{*}{$\begin{array}{l}\text { Residential area of the respondent } \\
\qquad(\text { yes }=1 ; \text { no }=0)\end{array}$} & Seoul & 0.226 & 0.418 & 0 & 1 \\
\hline & Region2 & & Gyeonggi, Incheon & 0.311 & 0.463 & 0 & 1 \\
\hline & Region3 & & Chungcheong & 0.092 & 0.289 & 0 & 1 \\
\hline & Region4 & & Jeonla, Jeju & 0.100 & 0.300 & 0 & 1 \\
\hline & Region5 & & $\begin{array}{l}\text { North Gyeongsang, } \\
\text { Gangwon }\end{array}$ & 0.123 & 0.328 & 0 & 1 \\
\hline & Region6 & & South Gyeongsang & 0.190 & 0.392 & 0 & 1 \\
\hline & Hh12 & \multirow{4}{*}{$\begin{array}{l}\text { The number of household members } \\
\qquad(\text { yes }=1 ; \text { no }=0)\end{array}$} & $1-2$ & 0.192 & 0.394 & 0 & 1 \\
\hline & Hh3 & & 3 & 0.277 & 0.447 & 0 & 1 \\
\hline & Hh4 & & 4 & 0.409 & 0.492 & 0 & 1 \\
\hline & Hh5 & & 5 or more & 0.123 & 0.328 & 0 & 1 \\
\hline & Kid & \multicolumn{2}{|l|}{$\begin{array}{l}\text { The presence of children } \\
\quad(\text { yes }=1 ; \text { no }=0)\end{array}$} & 0.587 & 0.492 & 0 & 1 \\
\hline & Job1 & \multirow{4}{*}{$\begin{array}{l}\text { Job of the respondent } \\
\quad(\text { yes }=1 ; \text { no }=0)\end{array}$} & Professional & 0.173 & 0.378 & 0 & 1 \\
\hline & Job2 & & Office & 0.449 & 0.497 & 0 & 1 \\
\hline & Job3 & & Service, sales & 0.157 & 0.363 & 0 & 1 \\
\hline & Job4 & & Others & 0.221 & 0.415 & 0 & 1 \\
\hline & Income & \multicolumn{2}{|c|}{ Log (monthly household total income) } & 6.097 & 0.500 & 3.219 & 6.697 \\
\hline
\end{tabular}

Notes: USD 1.0 = KRW 1143.4 at the time of survey.

\section{Empirical Results}

The ordered probit model was estimated using STATA 15.1. The estimation results presented in Table 2 provide insights on the market segments with high WTP for eco-labeled seafood. It is assumed that $L_{1}$ means the value of the maximum likelihood function for the unrestricted model and $L_{0}$ is the value of the maximum likelihood function when zero slope restriction are imposed. The likelihood ratio test statistic, $L R=2\left(L_{1}-L_{0}\right)$, is 442.94 , a value sufficiently large to reject the null hypothesis at the $1 \%$ level. Moreover, the result that the estimated threshold parameters are statistically significant at the $1 \%$ level implies that the ordered probit model is appropriate in this context. 
Table 2. Estimation results of the ordered probit model.

\begin{tabular}{|c|c|c|c|}
\hline Variables & Coefficients & Standard Errors & $z$-Values \\
\hline Salmon & 0.025 & 0.073 & 0.35 \\
\hline Tuna & 0.043 & 0.067 & 0.65 \\
\hline Octopus & -0.025 & 0.061 & -0.41 \\
\hline Outdoor & $0.097^{* *}$ & 0.048 & 2.02 \\
\hline Domestic & 0.018 & 0.054 & 0.34 \\
\hline Frequency & $0.118^{* * *}$ & 0.031 & 3.78 \\
\hline Fresh & 0.035 & 0.062 & 0.57 \\
\hline Price & $-0.233^{* * *}$ & 0.065 & -3.60 \\
\hline Confirm & $0.456^{* * *}$ & 0.031 & 14.89 \\
\hline Female & -0.001 & 0.045 & -0.03 \\
\hline Age30 & 0.092 & 0.077 & 1.20 \\
\hline Age40 & 0.054 & 0.083 & 0.65 \\
\hline Age50 & $0.155^{*}$ & 0.087 & 1.77 \\
\hline Age60 & 0.065 & 0.096 & 0.67 \\
\hline Region2 & $-0.122^{* *}$ & 0.057 & -2.13 \\
\hline Region3 & -0.030 & 0.083 & -0.37 \\
\hline Region4 & $-0.204^{* *}$ & 0.080 & -2.55 \\
\hline Region5 & 0.007 & 0.070 & 0.10 \\
\hline Region6 & $-0.278^{* * *}$ & 0.062 & -4.46 \\
\hline Hh3 & -0.106 & 0.073 & -1.46 \\
\hline Hh4 & -0.118 & 0.073 & -1.63 \\
\hline Hh5 & $-0.188^{* *}$ & 0.088 & -2.12 \\
\hline Kid & 0.097 & 0.066 & 1.48 \\
\hline Job1 & $-0.195^{* * *}$ & 0.071 & -2.73 \\
\hline Job2 & $-0.152 * *$ & 0.061 & -2.50 \\
\hline Job3 & -0.093 & 0.075 & -1.25 \\
\hline Income & $0.280^{* * *}$ & 0.047 & 5.91 \\
\hline$\mu_{1}$ & $0.555^{*}$ & 0.313 & 1.77 \\
\hline$\mu_{2}$ & $1.726^{* * *}$ & 0.297 & 5.81 \\
\hline$\mu_{3}$ & $3.332^{* * *}$ & 0.300 & 11.11 \\
\hline$\mu_{4}$ & $5.042^{* * *}$ & 0.307 & 16.45 \\
\hline Number of observations & & 2773 & \\
\hline Log-likelihood & & -2816.616 & \\
\hline LR statistic & & $442.940^{* * *}$ & \\
\hline
\end{tabular}

Notes: ${ }^{*}, * *$, and ${ }^{* * *}$ represent statistical significance at the $10 \%, 5 \%$ and $1 \%$ levels, respectively.

Given that the coefficients of species are found to be statistically insignificant, the respondents are more likely to have similar preferences for eco-labeled seafood. This result is different from the result obtained by Johnston et al. [3] and Wessells et al. [4] in the USA and Norway. Respondents treated all four species equally, considering their consumption preference for certified seafood. Those who prefer eating out showed a clear preference for eco-labeled seafood. The fish consumption frequency functioned as a significant variable of the demand for eco-labeled seafood, because respondents who consume more fish were pleased to select eco-labeled seafood as in Pérez-Ramírez et al. [19]. The negative sign for price indicates that, if consumers consider price to be an important consumption factor, their preference for eco-labeled seafood may decrease. The price premium has a negative impact on the probability of selecting eco-labeled seafood [3]. Respondents with low price elasticity of demand are likely to consume eco-labeled seafood more frequently. Given that price is obviously an important food choice factor, low-income consumers are highly sensitive to price [15].

Note that groups with higher preference for eco-labeled seafood consider the confirmation of origin as an important factor. Consumers who were concerned about the origin of seafood were more likely to be environment-friendly. They might perceive origin as a minimum baseline for sustainable production. Gender and age were found to be statistically insignificant factors in affecting consumer preference. It appears that respondents from Seoul have a higher preference for eco-labeled seafood 
than those from other regions. However, Jeonla, Jeju, and South Gyeongsang, where there is abundant fish production, showed a low preference. It is likely that the household income in Seoul is higher than in other regions, so they have more purchasing power. In addition, it can be seen that respondents in Seoul have good understanding of the environment due to relatively high education level. Respondents' geographic locations are significant factors affecting the consumption preference as in Wessells et al. [4] and Kumar et al. [9]. The demographic factor of the number of household members was found to be statistically insignificant, as in Kumar et al. [9].

In terms of respondents' occupation, respondents with professional or office occupation have a significantly lower probability of preferring eco-labeled seafood than individuals with other occupational statuses. The coefficients for Job1 and Job2 are estimated to be -0.195 and -0.152 , which are statistically significant at the $5 \%$ level. To check the statistical difference of the coefficients of Job1 and Job2, we can estimate the ordered probit model by omitting Job2 variable from independent variables as a reference category. According to the results of such case, the coefficients for Job1 and Job2 are found to be not statistically different. The coefficient of income is positive and statistically meaningful at the $1 \%$ level. Specifically, eco-labeled seafood means a normal good, and the positive coefficient for income agrees with micro-economic principle. In line with the Engel curve, the finding that higher income households prefer eco-labeled seafood reflects the effect of purchasing power.

Table 3 presents the marginal effects of the independent variables on the probabilities of consumption preference. The marginal effects add to zero for each independent variable among the five categories of consumption preference. With increasing consumption preference, a change in the sign of marginal effects from negative to positive reflects an increase in marginal utility, while a positive to negative change indicates a decrease in marginal utility [9].

Table 3. Marginal effects from the estimated ordered probit model.

\begin{tabular}{cccccc}
\hline Variables & Prefer $=\mathbf{0}$ & Prefer $=\mathbf{1}$ & Prefer $=\mathbf{2}$ & Prefer $=\mathbf{3}$ & Prefer $=\mathbf{4}$ \\
\hline Salmon & 0.000 & -0.002 & -0.006 & 0.006 & 0.003 \\
Tuna & -0.001 & -0.004 & -0.011 & 0.010 & 0.005 \\
Octopus & 0.000 & 0.002 & 0.006 & -0.006 & -0.003 \\
Outdoor & -0.001 & -0.009 & -0.025 & 0.023 & 0.012 \\
Domestic & 0.000 & -0.002 & -0.005 & 0.004 & 0.002 \\
Frequency & -0.002 & -0.011 & -0.030 & 0.028 & 0.015 \\
Fresh & 0.000 & -0.003 & -0.009 & 0.008 & 0.004 \\
Price & 0.003 & 0.022 & 0.059 & -0.055 & -0.029 \\
Confirm & -0.006 & -0.044 & -0.115 & 0.108 & 0.057 \\
Female & 0.000 & 0.000 & 0.000 & 0.000 & 0.000 \\
Age30 & -0.001 & -0.009 & -0.023 & 0.022 & 0.012 \\
Age40 & -0.001 & -0.005 & -0.014 & 0.013 & 0.007 \\
Age50 & -0.002 & -0.015 & -0.039 & 0.037 & 0.019 \\
Age60 & -0.001 & -0.006 & -0.016 & 0.015 & 0.008 \\
Region2 & 0.002 & 0.012 & 0.031 & -0.029 & -0.015 \\
Region3 & 0.000 & 0.003 & 0.008 & -0.007 & -0.004 \\
Region4 & 0.003 & 0.019 & 0.051 & -0.048 & -0.025 \\
Region5 & 0.000 & -0.001 & -0.002 & 0.002 & 0.001 \\
Region6 & 0.004 & 0.027 & 0.070 & -0.066 & -0.035 \\
Hh3 & 0.001 & 0.010 & 0.027 & -0.025 & -0.013 \\
Hh4 & 0.002 & 0.011 & 0.030 & -0.028 & -0.015 \\
Hh5 & 0.002 & 0.018 & 0.047 & -0.044 & -0.023 \\
Kid & -0.001 & -0.009 & -0.025 & 0.023 & 0.012 \\
Job1 & 0.002 & 0.019 & 0.049 & -0.046 & -0.024 \\
Job2 & 0.002 & 0.014 & 0.038 & -0.036 & -0.019 \\
Job3 & 0.001 & 0.009 & 0.024 & -0.022 & -0.012 \\
Income & -0.004 & -0.027 & -0.071 & 0.066 & 0.035 \\
\hline & & & & \\
\hline
\end{tabular}


If respondents consider price to be an important factor for consumption, the probability that they prefer labeled seafood over non-labeled seafood would decrease by $5.5 \%$. Respondents located in South Gyeongsang have a lower probability of preferring eco-labeled seafood. Moreover, respondents with higher income are more likely to prefer eco-labeled seafood.

\section{Conclusions}

This study analyzes individual-level consumption preferences for eco-labeled seafood in South Korea by employing an ordered probit model. The results are valuable from both applied and methodological perspectives. In practical terms, the survey gives an indication of respondents' preferences for eco-labeled seafood in Korea, as it is successful in eliciting the marginal effects for consumption preference attributes. Methodologically, this study is one of the few studies that estimate the preference function of eco-labeled seafood in Korea via an ordered probit model. The appropriate application of such model to the context of analysis is also highlighted.

The estimation results indicate that the coefficients of main consumption place, consumption frequency, the importance of price, the confirmation of origin, residential area, and household income are statistically significant. Respondents with low price elasticity of demand are likely to prefer eco-labeled seafood; those with lower preference tend to consider price as a more significant factor. In particular, these results were consistent with the direction of the effect of consumption frequency, household income, and price factor on preference for eco-labeled seafood as in the Mexican case [19]. Consumers highly concerned about the origin of seafood are more likely to accept eco-labeled seafood. Promotional activities underlining the origin of seafood can contribute to increased consumption. Moreover, marketing efforts and related government policies should concentrate on attracting consumers who fit such a profile.

This study provides significant managerial implications. From the estimation results, marketing managers can get useful information to design strategies to increase eco-labeled seafood consumption. In other words, they can concentrate on managerial endeavors to segments with higher probability of increasing consumption frequency. For example, marketing managers need to be interested in a new marketing strategy that targets adult men living in Seoul who have an interest in the origin of the fish. The results of this study can also be viewed in terms of consumer-based resource management policies. For example, the preference for eco-labeled seafood was lower at home rather than at restaurants; it was also lower in major fish production regions than in consumption regions such as Seoul. This suggests that the government should provide greater support to some regions to encourage eco-labeling.

For research purposes, this study is meaningful in that it employs micro survey data despite the limitations, and shows the feasibility of the application of the ordered probit model at least for the consumption of eco-labeled seafood. Thus, this study can contribute to widening the research spectrum of the existing literature on seafood preference. Although this study provides detailed information on individual-level consumption preference, the survey does not cover the actual level of WTP for eco-labeled seafood. Future research should include the actual WTP and apply them to the present framework. In this sense, we hope that this study will promote future research on eco-labeled seafood consumption in Korea.

Author Contributions: All the authors made contribution to this paper. B.-T.K. made the survey questionnaire and obtained estimation results; M.-K.L. conducted the literature review and revised the manuscript.

Funding: This research was supported by the Technology Innovation Program (Graduate School of Management of Technology) funded by the Ministry of Trade, Industry and Energy (N0001613).

Acknowledgments: The authors would like to thank FTA Implementation Support Center in Korea Maritime Institute for providing survey data.

Conflicts of Interest: The authors declare no conflict of interest. 


\section{References}

1. Food and Agriculture Organization. The State of World Fisheries and Aquaculture 2018; Food and Agriculture Organization of the United Nations: Rome, Italy, 2018.

2. Korea National Statistical Office. Fishery Production Survey; Korea National Statistical Office: Daejeon, Korea, 2018.

3. Johnston, R.J.; Wessells, C.R.; Donath, H.; Asche, F. Measuring consumer preferences for ecolabeled seafood: An international comparison. J. Agric. Resour. Econ. 2001, 26, 20-39.

4. Wessells, C.R.; Donath, H.; Johnston, R. Assessing consumer preferences for ecolabeled seafood: The influence of species, certifier, and household attributes. Am. J. Agric. Econ. 1999, 81, 1084-1089. [CrossRef]

5. Lee, J.S.; Eom, S.H.; Jeong, S.B.; Hwang, K.H. A Study on the Methods of Consumer-Based Fisheries Resources Management; Korea Maritime Institute: Busan, Korea, 2016.

6. Gudmundsson, E.; Wessells, C.R. Ecolabeling seafood for sustainable production: Implications for fisheries management. Mar. Resour. Econ. 2010, 15, 97-113. [CrossRef]

7. Erwann, C. Eco-labelling: A new deal for a more durable fishery management? Ocean Coast. Manag. 2009, 52, 250-257. [CrossRef]

8. Bennett, B.; D'Souza, G.; Borisova, T.; Amarasinghe, A. Willingness to consume genetically modified foods-The case of fish and seafood. Aquac. Econ. Manag. 2005, 9, 331-345. [CrossRef]

9. Kumar, G.; Quagrainie, K.; Engle, C. Factors that influence frequency of purchase of catfish by U.S. households in selected cities. Aquac. Econ. Manag. 2008, 12, 252-267. [CrossRef]

10. Quagrainie, K.; Hart, S.; Brown, P. Consumer acceptance of locally grown food: The case of Indiana aquaculture products. Aquac. Econ. Manag. 2008, 12, 54-70. [CrossRef]

11. Myers, J.J.; Govindasamy, R.; Ewart, J.W.; Liu, B.; You, Y.; Puduri, V.S.; O’Dierno, L.J. Consumer analysis in ethnic live seafood markets in the Northeast region of the United States. J. Food Prod. Mark. 2010, 16, 147-165. [CrossRef]

12. Puduri, V.S.; Govindasamy, R.; Myers, J.J.; O'Dierno, L.J. Demand for live aquatic products in the Mid-Atlantic states: An ordered probit analysis towards consumers' preferences. Aquac. Econ. Manag. 2010, 14, 30-42. [CrossRef]

13. Quagrainie, K.; Xing, A.; Hughes, K.G. Factors influencing the purchase of live seafood in the North Central region of the United States. Mar. Resour. Econ. 2011, 26, 59-74. [CrossRef]

14. Thapa, G.; Dey, M.M.; Engle, C. Consumer preferences for live seafood in the Northeastern region of USA: Results from Asian ethnic fish market survey. Aquac. Econ. Manag. 2015, 19, 210-225. [CrossRef]

15. Thong, N.T.; Solgaard, H.S. Consumer's food motives and seafood consumption. Food Qual. Prefer. 2017, 56, 181-188. [CrossRef]

16. Jaffry, S.; Pickering, H.; Ghulam, Y.; Whitmarsh, D.; Wattage, P. Consumer choices for quality and sustainability labelled seafood products in the UK. Food Policy 2004, 29, 215-228. [CrossRef]

17. Xu, P.; Zeng, Y.; Fong, Q.; Lone, T.; Liu, Y. Chinese consumers' willingness to pay for green- and eco-labeled seafood. Food Control 2012, 28, 74-82. [CrossRef]

18. Uchida, H.; Onozaka, Y.; Morita, T.; Managi, S. Demand for ecolabeled seafood in the Japanese market: A conjoint analysis of the impact of information and interaction with other labels. Food Policy 2014, 44, 68-76. [CrossRef]

19. Pérez-Ramírez, M.; Almendarez-Hernández, M.A.; Avilés-Polanco, G.; Beltrán-Morales, L.F. Consumer acceptance of eco-labeled fish: A Mexican case study. Sustainability 2015, 7, 4625-4642. [CrossRef]

20. Jonell, M.; Crona, B.; Brown, K.; Rönnbäck, P.; Troell, M. Eco-labeled seafood: Determinants for (blue) green consumption. Sustainability 2016, 8, 884. [CrossRef]

21. Richter, I.; Thøgersen, J.; Klöckner, C.A. Sustainable seafood consumption in action: Relevant behaviors and their predictors. Sustainability 2017, 9, 2313. [CrossRef]

22. Greene, W.H.; Hensher, D.A. Modeling Ordered Choices: A Primer; Cambridge University Press: Cambridge, UK, 2010.

23. Greene, W.H. Econometric Analysis, 5th ed.; Prentice Hall: Upper Saddle River, NJ, USA, 2003.

24. Korea Development Institute. Preliminary Feasibility Study General Guideline, 5th ed.; Korea Development Institute: Seoul, Korea, 2008. 
25. Korea Rural Economic Institute. Table on Demand and Supply of Food 2016; Korea Rural Economic Institute: Naju, Korea, 2017.

26. Korea National Statistical Office. Household Projection; Korea National Statistical Office: Daejeon, Korea, 2018.

27. Korea National Statistical Office. Household Income and Expenditure Survey; Korea National Statistical Office: Daejeon, Korea, 2018. 